\title{
Novel risk factors for recurrent biliary obstruction and pancreatitis after metallic stent placement in pancreatic cancer
}

다(1)웅

\author{
Authors \\ Tsuyoshi Takeda, Takashi Sasaki, Takafumi Mie, Takaaki Furukawa, Ryo Kanata, Akiyoshi Kasuga, Masato \\ Matsuyama, Masato Ozaka, Naoki Sasahira
}

Institution

Department of Hepato-Biliary-Pancreatic Medicine, Cancer Institute Hospital of Japanese Foundation for Cancer

Research, Tokyo, Japan

submitted 28.4.2020

accepted after revision 3.8 .2020

Bibliography

Endoscopy International Open 2020; 08: E1603-E1610

DOI 10.1055/a-1244-1989

ISSN 2364-3722

(c) 2020. The Author(s).

This is an open access article published by Thieme under the terms of the Creative Commons Attribution-NonDerivative-NonCommercial License, permitting copying and reproduction so long as the original work is given appropriate credit. Contents may not be used for commecial purposes, or adapted, remixed, transformed or built upon. (https://creativecommons.org/licenses/by-nc-nd/4.0/)

Corresponding author

Takashi Sasaki, MD, PhD, Department of Hepato-BiliaryPancreatic Medicine, Cancer Institute Hospital of Japanese Foundation for Cancer Research, 3-8-31, Ariake, Koto, Tokyo, 135-8550, Japan

Fax: +81-3-3520-0141

sasakit-tky@umin.ac.jp

\section{ABSTRACT}

Background and study aims Self-expandable metallic stents (SEMS) are now widely used even for patients with borderline resectable (BR) pancreatic cancer (PC), as neoadjuvant therapy has become common. Therefore, we conducted this study to evaluate safety of SEMS placement in the population including BR PC and to explore risk factors for recurrent biliary obstruction (RBO), pancreatitis, and cholecystitis.

Patients and methods We retrospectively investigated consecutive patients with PC who received initial SEMS between January 2015 and March 2019. We compared time to RBO (TRBO), causes of RBO, and stent-related adverse events (AEs) according to resectability status. Univariate and multivariate analyses were performed to explore risk factors for TRBO, pancreatitis, and cholecystitis.

Results A total of 135 patients were included (BR 31 and unresectable [UR] 104). Stent-related AEs occurred in 39 patients: pancreatitis 14 (mild/moderate/severe 1/6/7), cholecystitis 12, and non-occluding cholangitis 13. TRBO, causes of RBO, and stent-related AEs were not significantly different according to resectability status. Overall rate of RBO was higher in UR PC due to the longer follow-up period. Sharp common bile duct (CBD) angulation was an independent risk factor for short duration of TRBO. High pancreatic volume index and SEMS of high axial force were independent risk factors for pancreatitis, whereas tumor involvement to orifice of cystic duct was the only risk factor for cholecystitis.

Conclusions We demonstrated that SEMS can be safely deployed even in patients with BR PC. Sharp CBD angulation and high pancreatic volume index were identified as novel risk factors for RBO and pancreatitis, respectively, after SEMS placement.

\section{Introduction}

Pancreatic cancer (PC) is the third leading cause of cancer-related death in the United States [1] and the fourth in Japan [2]. Despite recent advances in chemotherapy and surgical techniques, the prognosis for PC remains dismal [3]. Surgical resection with negative margins is the only chance for cure, although approximately $80 \%$ of patients who undergo resection experi- ence local or metastatic recurrence $[4,5]$. Neoadjuvant chemoradiotherapy (NACRT) and chemotherapy (NAC) are accepted as new treatment strategies for borderline resectable (BR) $P C$ due to improved margin negative resection rate and median overall survival [6-10]. Recently, neoadjuvant therapy is becoming a new trend even in resectable (R) PC $[11,12]$.

Malignant biliary obstruction (MBO) is a common clinical manifestation in patients with pancreatic head cancer. Endo- 
scopic placement of a self-expandable metallic stent (SEMS) is the standard treatment for distal MBO in patients with unresectable (UR) PC due to the long stent patency compared to plastic stents $[13,14]$. Even for patients with BR or R PC who have a prolonged time to surgery, preoperative biliary drainage is considered essential, and several studies have reported the efficacy of SEMS placement in this setting [15-20].

However, data regarding the safety of SEMS placement in BR PC are limited. In addition, there are no studies that have evaluated risk factors for recurrent biliary obstruction (RBO), pancreatitis, and cholecystitis in the population including BR PC. We consider that incidence of RBO and stent-related adverse events (AEs), such as pancreatitis and cholecystitis, differs in accordance with the resectability status of PC. First, we hypothesize that patients with BR PC tend to have a larger pancreas volume and preserved exocrine pancreas function compared to UR PC, and consequently have an increased risk for post-endoscopic retrograde cholangiopancreatography (ERCP) pancreatitis. Second, we speculate that RBO might be influenced by the resectability status of $P C$, including factors such as the angulation of the common bile duct (CBD).

Therefore, we conducted this retrospective study to evaluate the safety of SEMS placement according to the resectability status of PC (BR vs UR). We also explored risk factors for RBO, pancreatitis, and cholecystitis after SEMS placement in the population, including both BR and UR PC. Furthermore, we included new parameters such as pancreas volume index and CBD angulation.

\section{Patients and methods}

\section{Patients}

We retrospectively analyzed consecutive patients with PC who underwent fully-covered SEMS (FCSEMS) placement for distal MBO at our institution between January 2015 and March 2019. Only patients who received initial transpapillary SEMS were included in this study. Excluded patients were as follows: (1) patients who received a SEMS above the papilla; (2) patients who received a duodenal stent across the papilla; (3) patients with surgically altered anatomy; and (4) patients who were lost to follow-up or died within 2 weeks due to cancer itself. Furthermore, patients with R PC were also excluded in this study because we didn't place a SEMS for those who were candidates for upfront surgery. Written informed consent of the procedure was obtained from all patients in accordance with the declaration of Helsinki. This study was approved by the ethics committee of our institution.

\section{Diagnosis, definition and classification}

Each patient underwent computed tomography (CT) for tumor staging. Resectability status was defined according to the National Comprehensive Cancer Network (NCCN) guideline [21]. Histological confirmation was obtained from every patient either by bile duct biopsy (or cytology), endoscopic ultrasound fine-needle aspiration, or liver biopsy.

CBD angulation was defined as the first angulation from the ampullary orifice along the course of CBD and was measured on cholangiogram obtained in the prone position before the deployment of a SEMS [22] ( Fig.1a). Pancreatic volume index was calculated as the sum of lengths of the normal pancreatic parenchyma measured at three sections as follows: the level of aorta, left adrenal gland, and left kidney (> Fig. 1b). Tumor involvement to orifice of cystic duct (OCD) was evaluated by the results of $C T$, magnetic resonance cholangiopancreatography, and endoscopic retrograde cholangiography. Tumor involvement to the pancreatic duct (PD) was defined as PD obstruction with upstream PD dilation.

The FCSEMS used in this study were as follows: HANAROSTENT Biliary (M.I.Tech, Soul, Korea), Evolution Biliary Controlled-Release Stent-Fully Covered (Cook Medical, Bloomington, USA), Niti-S SUPREMO-10 stent (TaeWoong Medical, Soul, Korea), Niti-S ComVi Biliary Stent (TaeWoong Medical, Soul, Korea). Evolution Biliary Controlled-Release Stent-Fully Covered was categorized as high axial force (AF) stent and the other three stents were categorized as low AF stents.

\section{Endoscopic interventions}

ERCP was performed using a therapeutic duodenoscope (JF260, TJF260; Olympus Medical Systems, Tokyo, Japan) under moderate sedation with intravenous pethidine and midazolam. We basically performed endoscopic sphincterotomy (EST) with a small to moderate-sized incision and inserted an endoscopic nasobiliary drainage (ENBD) tube in the first session because of reasons such as cholangitis and undetermined biliary stricture. After jaundice or cholangitis subsided, we then deployed a SEMS under fluoroscopic guidance in the second session.

For patients with BR PC, in order to achieve a successful biliary anastomosis during pancreatoduodenectomy, we usually placed a SEMS at least $2 \mathrm{~cm}$ below the bifurcation of the hepatic duct. On the other hand, for patients with UR PC, we typically selected a long SEMS because of concern about stent-related AEs such as kinking.

Prophylactic rectal nonsteroidal anti-inflammatory drugs (NSAIDs) were used at the discretion of each endoscopist, and prophylactic pancreatic duct stent placement was not performed in any of the patients.

\section{Chemotherapy}

For patients with BR PC, we administered four cycles of gemcitabine plus nab-paclitaxel combination therapy (gemcitabine, $1000 \mathrm{mg} / \mathrm{m}^{2}$, nab-paclitaxel, $125 \mathrm{mg} / \mathrm{m}^{2}$, on days 1,8 , and 15 every 4 weeks). After four cycles of NAC were completed, a CT was performed for restaging and two experienced radiologists evaluated the degree of vascular involvement and radiologic response. The final decision to perform surgical exploration was determined by an expert panel consisting of medical oncologists, surgeons, and radiologists.

For patients with UR PC, we administered either of the following regimens considering the patient age, Eastern Cooperative Oncology Group performance status, and comorbidities: (1) gemcitabine plus nab-paclitaxel combination therapy; (2) modified FOLFIRINOX (oxaliplatin $85 \mathrm{mg} / \mathrm{m}^{2}$, leucovorin, $400 \mathrm{mg} / \mathrm{m}^{2}$, irinotecan, $150 \mathrm{mg} / \mathrm{m}^{2}$, infusional $5-\mathrm{FU}$, 

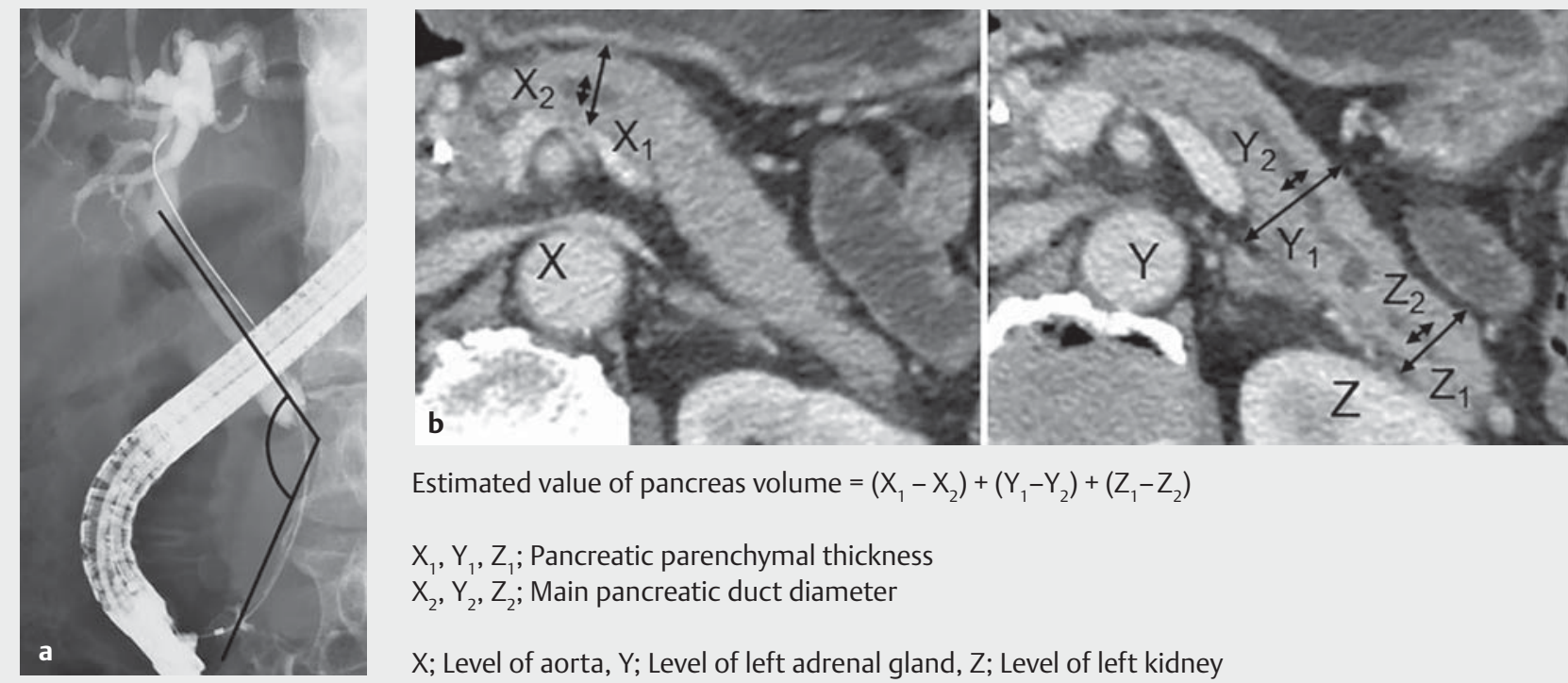

Estimated value of pancreas volume $=\left(X_{1}-X_{2}\right)+\left(Y_{1}-Y_{2}\right)+\left(Z_{1}-Z_{2}\right)$

$\mathrm{X}_{1}, \mathrm{Y}_{1}, \mathrm{Z}_{1}$; Pancreatic parenchymal thickness

$X_{2}, Y_{2}, Z_{2}$; Main pancreatic duct diameter

X; Level of aorta, Y; Level of left adrenal gland, Z; Level of left kidney

- Fig. 1 a Measurement of CBD angulation and $\mathbf{b}$ estimated value of normal pancreas volume. CBD, common bile duct.

$2400 \mathrm{mg} / \mathrm{m}^{2}$, every 2 weeks); (3) gemcitabine monotherapy; or (4) S-1 monotherapy.

\section{Evaluation}

Evaluation of SEMS was defined according to Tokyo Criteria 2014 [23]. RBO was defined as a composite endpoint of either occlusion or migration, and time to RBO (TRBO) was defined as the time from stent placement to RBO. Patients who were lost to follow up, removed the stent, or died without RBO were treated as censored cases at the time of the last follow-up, stent removal, or death. Complications other than RBO were categorized as early ( $\leq 30$ days after SEMS placement) and late ( $\geq 31$ days after SEMS placement) according to Tokyo criteria. The severity of adverse events were graded according to the American Society of Gastrointestinal Endoscopy lexicon guidelines [24].

First, we compared TRBO, causes of RBO, and stent-related AEs according to the resectability status of PC. Second, we evaluated factors affecting TRBO using Cox proportional hazards model. Finally, we explored risk factors for pancreatitis and cholecystitis in the population including both BR and UR PC. Patients who had a history of cholecystectomy were excluded in the evaluation of cholecystitis.

\section{Statistical analysis}

Continuous variables are presented as median (range), and were compared using Mann-Whitney $U$ test or Kruskal-Wallis test as appropriate. Categorical variables are described as absolute numbers (proportions), and were analyzed using $\mathrm{X}^{2}$ test or Fisher's exact test as appropriate. TRBO was estimated using the Kaplan-Meier method and Kaplan-Meier curves were compared by the log-rank test. Multivariate analysis was conducted using the cox proportional hazards model to identify risk factors for TRBO. The following eight variables were assessed by univariate analysis to identify risk factors for pancreatitis: resectability status (BR vs. UR), tumor involvement to PD (yes vs. no), pancreatic volume index ( $\geq 24 \mathrm{~mm}$ vs. $<24 \mathrm{~mm}$ ), type of SEMS (high AF vs. low AF), length of SEMS $(\leq 6 \mathrm{~cm}$ vs. $>6 \mathrm{~cm}$ ), EST before SEMS placement (yes vs. no), contrast injection into PD (yes vs. no), prophylactic rectal NSAIDs use (yes vs. no). The following seven variables were investigated by univariate analysis to identify risk factors for cholecystitis: resectability status (BR vs. UR), tumor involvement to OCD (yes vs. no), CBD angulation ( $\leq 136$ degrees vs. > 136 degrees), gallbladder stone (yes vs. no), type of SEMS (high AF vs. low AF), length of SEMS $(\leq 6 \mathrm{~cm}$ vs. $>6 \mathrm{~cm})$, OCD occlusion by SEMS (yes vs. no). Cutoff values for pancreatic volume index and CBD angulation were determined by the receiver operating characteristic curve. Factors with $P<0.10$ were included in the multivariate analysis. Statistical tests were two-sided and $P<0.05$ was considered statistically significant. Statistical analysis was carried out using the EZR software version 1.40 [25].

\section{Results}

\section{Patient characteristics}

A total of 160 consecutive patients with PC underwent initial transpapillary fully covered SEMS placement at our institution between January 2015 and March 2019. Twenty-five patients were excluded for reasons written above, and we analyzed the remaining 135 patients ( $\mathbf{F i g . 2}$ ). Forty-four patients (33\%) received SEMS in the first session, and the remaining 91 patients (67\%) received SEMS in the second session with a median interval of 5 days. Comparison of patient characteristics according to resectability status is summarized in $>$ Table 1 . Although patients with $B R P C$ tended to have a smaller primary tumor size (32 mm vs. $37 \mathrm{~mm}, P=0.09$ ), pancreatic volume index (24 mm vs. $21 \mathrm{~mm}, P=0.39$ ) was not statistically different between the 


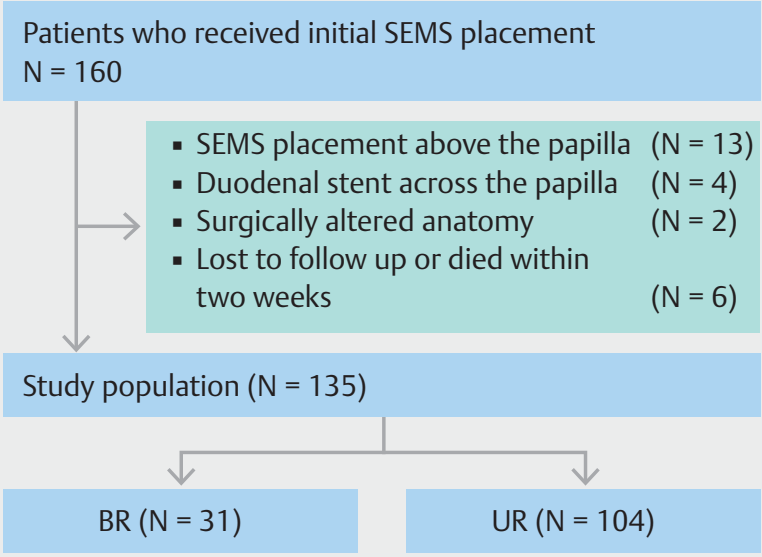

- Fig. 2 Patient flowchart. SEMS, self-expandable metallic stent; $\mathrm{BR}$, borderline resectable; UR, unresectable.

two groups. Since the strategy of SEMS deployment was different, patients with BR PC had a higher likelihood of receiving a shorter SEMS $(P=0.02)$ and had a lower probability of OCD occlusion by SEMS $(P<0.01)$. Furthermore, patients with BR PC tended to have a higher degree of CBD angulation compared to patients with UR PC (140 degrees vs. 136 degrees, $P=0.06$ ). Rates of tumor involvement to OCD or PD, SEMS stent type, and contrast injection into PD were not statistically different between the two groups.

\section{Comparison of TRBO, causes of RBO and stent related adverse events according to the resectability status}

RBO occurred in $35 \%$ of the entire cohort. Median TRBO was not statistically different between the two groups (317 days vs. 301 days, $P=0.34$ ) ( Fig. 3 ). Causes of RBO according to the resectability status are shown in $>$ Table 2 . Since BR PC patients without RBO get censored at the time of pancreatic resection (median follow up time from the date of SEMS placement to the date of pancreatic surgery or the date of the last follow up were 140 days for BR PC patients and 239 days for UR PC patients), overall rate of RBO was lower in BR PC patients (19\% vs. $39 \%, P=0.05)$. Complete stent migration occurred in three patients only in UR PC at a median interval of 216 days (range, 175 to 642 days). Stent-related AEs occurred in 39 patients: pancreatitis 14 (mild 1 , moderate 6 , and severe 7 ), cholecystitis 12 (moderate 7 and severe 5), and non-occluding cholangitis 13 ( Table 3). Stent related adverse events other than RBO were not statistically different between the two groups (26\% vs. $30 \%, P=0.82$ ).

\section{Risk factors for TRBO, pancreatitis, and cholecystitis}

Univariate and multivariate analyses of risk factors for TRBO are summarized in $>$ Table 4. CBD angulation $\leq 130$ degree (hazard ratio [HR], 2.48; $95 \%$ confidence interval $[\mathrm{Cl}], 1.38$ to $4.49 ; P<$ 0.01 ) was an independent risk factor for shorter duration of TRBO.
- Table 1 Comparison of patient characteristics according to the resectability status $(n=135)$.

\begin{tabular}{|c|c|c|c|}
\hline & $\begin{array}{l}\text { BR } \\
(n=31)\end{array}$ & $\begin{array}{l}\text { UR } \\
(n=104)\end{array}$ & $P$ value \\
\hline Gender, male & $14(45 \%)$ & $52(50 \%)$ & 0.69 \\
\hline Age, years & $70(36-78)$ & $67(22-87)$ & 0.47 \\
\hline Primary tumor size, mm & $32(19-55)$ & $37(14-84)$ & 0.09 \\
\hline Post-cholecystectomy & $4(13 \%)$ & $8(8 \%)$ & 0.47 \\
\hline Gallbladder stone & $1(3 \%)$ & $14(13 \%)$ & 0.19 \\
\hline $\begin{array}{l}\text { Tumor involvement to } \\
\text { OCD }\end{array}$ & $3(10 \%)$ & $14(13 \%)$ & 0.76 \\
\hline Tumor involvement to PD & $29(94 \%)$ & $93(89 \%)$ & 0.73 \\
\hline CBD angulation, degree & $\begin{array}{l}140 \\
(116-158)\end{array}$ & $\begin{array}{l}136 \\
(104-166)\end{array}$ & 0.06 \\
\hline $\begin{array}{l}\text { Pancreatic volume index, } \\
\mathrm{mm}\end{array}$ & $24(7-56)$ & $21(0-60)$ & 0.39 \\
\hline SEMS, stent type, high AF & $2(6 \%)$ & $19(18 \%)$ & 0.16 \\
\hline $\begin{array}{l}\text { SEMS, stent diameter, } 10 \\
\mathrm{~mm} / 8 \mathrm{~mm}\end{array}$ & $31 / 0$ & $103 / 1$ & 1.00 \\
\hline SEMS, stent length $\leq 6 \mathrm{~cm}$ & $27(87 \%)$ & $68(65 \%)$ & 0.02 \\
\hline OCD occlusion by SEMS & $17(55 \%)$ & $91(88 \%)$ & $<0.01$ \\
\hline Contrast injection into PD & $0(0 \%)$ & $2(2 \%)$ & 1.00 \\
\hline $\begin{array}{l}\text { EST before SEMS place- } \\
\text { ment }\end{array}$ & $31(100 \%)$ & $103(99 \%)$ & 1.00 \\
\hline $\begin{array}{l}\text { Prophylactic rectal } \\
\text { NSAIDs }\end{array}$ & $16(52 \%)$ & $47(45 \%)$ & 0.55 \\
\hline $\begin{array}{l}\text { Presence of a duodenal } \\
\text { stent }\end{array}$ & $0(0 \%)$ & $5(5 \%)$ & 0.59 \\
\hline Chemotherapy & $30(97 \%)$ & $87(84 \%)$ & 0.07 \\
\hline $\begin{array}{l}\text { Pancreatic resection after } \\
\text { chemotherapy }\end{array}$ & $19(61 \%)$ & $2(2 \%)$ & $<0.01$ \\
\hline $\begin{array}{l}\text { Median follow up time } \\
\text { from SEMS placement to } \\
\text { pancreatic resection or } \\
\text { the last follow up }\end{array}$ & $\begin{array}{l}140 \\
(44-482)\end{array}$ & $\begin{array}{l}239 \\
(18-1150)\end{array}$ & $<0.05$ \\
\hline \multicolumn{4}{|c|}{$\begin{array}{l}\text { Continuous variables are expressed as median (range) and categorical vari- } \\
\text { ables are expressed as absolute numbers (proportions). } \\
\text { BR, borderline resectable; UR, unresectable; OCD, orifice of cystic duct; PD, } \\
\text { pancreatic duct; CBD, common bile duct; AF, axial force; EST, endoscopic } \\
\text { sphincterotomy; NSAIDs, nonsteroidal anti-inflammatory drugs. }\end{array}$} \\
\hline
\end{tabular}

Univariate and multivariate analyses of risk factors for pancreatitis are shown in $>$ Table 5 . Pancreatic volume index (odds ratio [OR], 5.12; $95 \% \mathrm{Cl}, 1.30$ to $20.2 ; P=0.02$ ) and SEMS of high AF (OR, 4.50; $95 \% \mathrm{Cl}, 1.24$ to $16.4 ; P=0.02$ ) were independent risk factors for pancreatitis. Conversely, the resectability status was not an independent risk factor for pancreatitis.

Univariate and multivariate analyses of risk factors for cholecystitis in 123 patients (excluding patients who had a history of cholecystectomy from the whole population) are shown in 


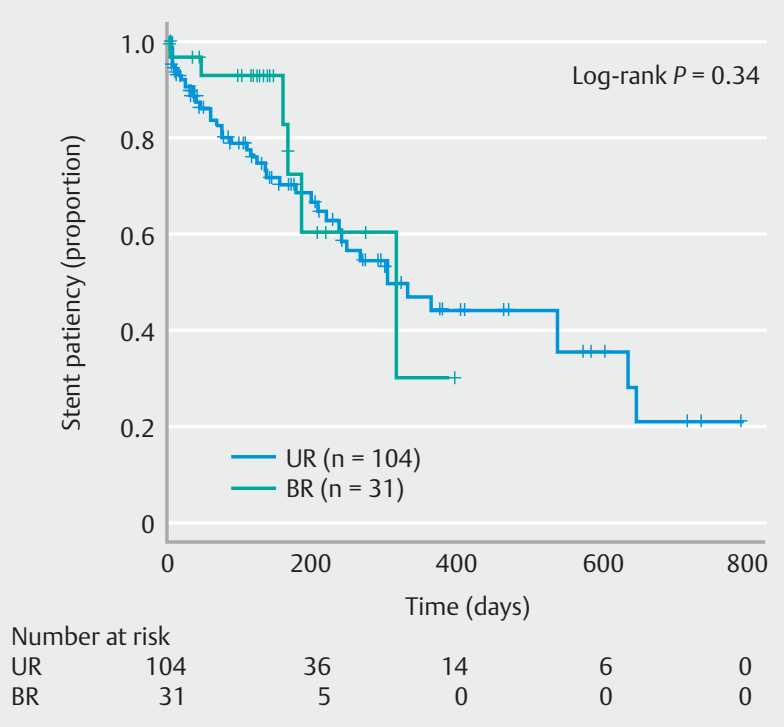

- Fig. 3 Kaplan-Meier curves of time to recurrent biliary obstruction according to resectability status. BR, borderline resectable; UR, unresectable.

- Table 6. Only tumor involvement to OCD (OR, 38.6; $95 \% \mathrm{Cl}$, 8.69 to $172 ; P<0.01$ ) was an independent risk factor for cholecystitis.

\section{Discussion}

This retrospective study evaluated the safety of SEMS placement for $\mathrm{PC}$ according to the resectability status of the primary tumor. Our results showed that TRBO, causes of RBO and stent related adverse events were not significantly different depending on the resectability status (BR vs UR). We also clarified risk factors for RBO, pancreatitis, and cholecystitis in the population including both BR and UR PC. We demonstrated that sharp CBD angulation ( $\mathrm{CBD}$ angulation $\leq 130$ degree [HR, 2.48; $P<$ $0.01]$ ) was an independent risk factor for shorter duration of TRBO. Moreover, we showed that high pancreatic volume index (pancreatic volume index $\geq 24 \mathrm{~mm}[\mathrm{OR}, 5.12 ; P=0.02]$ ) and SEMS of high AF (OR, 4.50; $P=0.02)$ were independent risk factors for pancreatitis, whereas tumor involvement to OCD (OR, 38.6; $P<0.01$ ) was the only independent risk factor for cholecystitis. The novelty of this study is as follows. First, we investigated the safety of SEMS placement according to the resectability status in the population including both BR and UR PC. Second, we included pancreatic volume index and CBD angulation in the evaluation of risk factors for RBO, pancreatitis, and cholecystitis. To the best of our knowledge, this is the first study to demonstrate that sharp CBD angulation and high pancreatic volume index were independent risk factors for RBO and pancreatitis, respectively, after SEMS placement in PC patients.

RBO occurred in $35 \%$ of patients (47/135) after SEMS placement in our study. However, little is known about risk factors for RBO, especially in distal MBO [26]. Our study is Important
- Table 2 Comparison of causes of RBO according to the resectability status $(n=135)$.

\begin{tabular}{|c|c|c|c|}
\hline Causes of RBO & $\begin{array}{l}\text { BR } \\
(n=31)\end{array}$ & $\begin{array}{l}\text { UR } \\
(n=104)\end{array}$ & $P$ value \\
\hline Occlusion & $3(10 \%)$ & $20(19 \%)$ & 0.28 \\
\hline - Biliary sludge & $1(3 \%)$ & $9(9 \%)$ & \\
\hline - Food impaction & $1(3 \%)$ & $9(9 \%)$ & \\
\hline - Tumor ingrowth & $0(0 \%)$ & $2(2 \%)$ & \\
\hline - Tumor overgrowth & $1(3 \%)$ & $0(0 \%)$ & \\
\hline Kinking & $1(3 \%)$ & $2(2 \%)$ & 0.55 \\
\hline Migration & $2(6 \%)$ & $19(18 \%)$ & 0.16 \\
\hline - Inward migration & $0(0 \%)$ & $5(5 \%)$ & \\
\hline - Outward migration & $2(6 \%)$ & $14(13 \%)$ & \\
\hline $\begin{array}{l}\text { - Complete outward } \\
\text { migration }\end{array}$ & $0(0 \%)$ & $3(3 \%)$ & \\
\hline Total & $6(19 \%)$ & 41 (39\%) & 0.05 \\
\hline
\end{tabular}

RBO, recurrent biliary obstruction; BR, borderline resectable; UR, unresectable

- Table 3 Comparison of stent related complications according to the resectability status $(n=135)$.

\begin{tabular}{|c|c|c|c|}
\hline Complications & $\begin{array}{l}\text { BR } \\
(n=31)\end{array}$ & $\begin{array}{l}\text { UR } \\
(n=104)\end{array}$ & $P$ value \\
\hline Pancreatitis & $5(16 \%)$ & $9(9 \%)$ & 0.31 \\
\hline - Time ${ }^{1}$, early / late & $3 / 2$ & $8 / 1$ & \\
\hline $\begin{array}{l}\text { - Severity }{ }^{2}, \text { mild/ } \\
\text { moderate/severe }\end{array}$ & $0 / 2 / 3$ & $1 / 4 / 4$ & \\
\hline Cholecystitis & $3(10 \%)$ & $9(9 \%)$ & 1.00 \\
\hline - Time ${ }^{1}$, early / late & $2 / 1$ & $6 / 3$ & \\
\hline $\begin{array}{l}\text { Severity }{ }^{2}, \text { mild/ } \\
\text { moderate/severe }\end{array}$ & $0 / 3 / 0$ & $0 / 4 / 5$ & \\
\hline Non-occluding cholangitis & $2(6 \%)$ & $11(11 \%)$ & 0.73 \\
\hline Liver abscess & $1(3 \%)$ & $1(1 \%)$ & 0.41 \\
\hline Abscess around the bile duct & $0(0 \%)$ & $1(1 \%)$ & 1.00 \\
\hline Total & $8(26 \%)$ & $31(30 \%)$ & 0.82 \\
\hline \multicolumn{4}{|c|}{$\begin{array}{l}\text { BR, borderline resectable; UR, unresectable. } \\
{ }^{1} \text { Time from SEMS placement to the onset of pancreatitis and cholecystitis } \\
\text { was divided into early ( } \leq 30 \text { days) and late ( } \geq 31 \text { days) according to Tokyo } \\
\text { criteria. } \\
{ }^{2} \text { Severity of pancreatitis and cholecystitis was graded according to the } \\
\text { American Society of Gastrointestinal Endoscopy lexicon guidelines. }\end{array}$} \\
\hline
\end{tabular}

because we identified sharp CBD angulation as a novel risk factor for shorter duration of TRBO. Based on the fact that sharp CBD angulation is considered as a risk factor for recurrent CBD stones $[27,28]$, angulated CBD may possibly reflect cholestasis and predispose to RBO. Moreover, we hypothesize that sharp CBD angulation might increase the risk of kinking or migration. 
- Table4 Univariate and multivariate analyses for time to recurrent biliary obstruction (TRBO) $(n=135)$.

\begin{tabular}{|c|c|c|c|c|c|c|}
\hline & & \multicolumn{2}{|l|}{ Univariate } & \multicolumn{3}{|l|}{ Multivariate } \\
\hline & & TRBO, day & $P$ value & Hazard ratio & $95 \% \mathrm{Cl}$ & $P$ value \\
\hline \multirow[t]{2}{*}{ Resectability status } & BR & 317 & 0.34 & & & \\
\hline & UR & 301 & & & & \\
\hline \multirow[t]{2}{*}{ CBD angulation } & $\leq 130$ degree & 185 & $<0.01$ & 2.48 & $1.38-4.49$ & $<0.01$ \\
\hline & $>130$ degree & 534 & & & & \\
\hline \multirow[t]{2}{*}{ SEMS type } & High AF & 185 & 0.06 & 1.96 & $0.96-4.02$ & 0.07 \\
\hline & Low AF & 359 & & & & \\
\hline \multirow[t]{2}{*}{ SEMS length } & $\leq 6 \mathrm{~cm}$ & 359 & 0.13 & & & \\
\hline & $>6 \mathrm{~cm}$ & 244 & & & & \\
\hline \multirow[t]{2}{*}{ Presence of a duodenal stent } & Yes & 33 & 0.40 & & & \\
\hline & No & 317 & & & & \\
\hline \multirow[t]{2}{*}{ Pancreatic surgery after chemotherapy } & Yes & NA & 0.12 & & & \\
\hline & No & 301 & & & & \\
\hline
\end{tabular}

- Table 5 Univariate and multivariate analyses of risk factors for pancreatitis $(n=135)$.

\begin{tabular}{|c|c|c|c|c|c|c|c|}
\hline & & \multicolumn{3}{|l|}{ Univariate } & \multicolumn{3}{|c|}{ Multivariate } \\
\hline & & Odds ratio & $95 \% \mathrm{Cl}$ & $P$ value & Odds ratio & $95 \% \mathrm{Cl}$ & $P$ value \\
\hline Resectability status & BR & 2.03 & $0.63-6.58$ & 0.24 & & & \\
\hline Tumor involvement to PD & Yes & 0.33 & $0.08-1.38$ & 0.13 & & & \\
\hline Pancreatic volume index & $\geq 24 \mathrm{~mm}$ & 4.40 & $1.17-16.6$ & 0.03 & 5.12 & $1.30-20.2$ & 0.02 \\
\hline SEMS type & high AF & 3.65 & $1.08-12.3$ & 0.04 & 4.50 & $1.24-16.4$ & 0.02 \\
\hline SEMS length & $\leq 6 \mathrm{~cm}$ & 0.73 & $0.23-2.34$ & 0.60 & & & \\
\hline EST & Yes & 672000 & $0-$ & 0.99 & & & \\
\hline Contrast injection into PD & Yes & 9.23 & $0.55-156$ & 0.12 & & & \\
\hline Rectal NSAIDs & Yes & 2.23 & $0.71-7.06$ & 0.17 & & & \\
\hline
\end{tabular}

Pancreatitis occurred in $10.4 \%$ of patients (14/135) after SEMS placement. Nine patients $(6.7 \%, 9 / 135)$ developed pancreatitis on the following day, a rate similar to that in previous reports $[13,17]$. Interestingly, of the 14 patients, three $(21.4 \%$, $3 / 14$ ) developed late-onset pancreatitis more than 30 days (39 to 118 days) after SEMS placement, which is extremely late compared to previous reports $[17,29]$. One patient had UR PC and the other two patients had BR PC. This late onset of pancreatitis might be caused by the preserved pancreas volume (pancreatic volume index: late onset of pancreatitis cases, median $38 \mathrm{~mm}$; early onset of pancreatitis cases, median $26 \mathrm{~mm}$; non-pancreatitis cases, median $21 \mathrm{~mm}$ ), thus caution should be taken in this group of patients. Several risk factors for pancrea- titis after SEMS placement have been reported [29-31]. Contrast injection into PD was reported as a significant risk factor for pancreatitis [29], which was inconsistent with our results. Because we typically deployed a SEMS in the second session after drainage by ENBD, incidence of contrast injection into PD was much lower in our study (1\%) compared to their study (27\%), which may explain the discrepancy. SEMS of high AF was also an independent risk factor for pancreatitis in our study, which is consistent with previous reports [30]. Tumor involvement to PD theoretically causes subsequent distal pancreas atrophy and decreased exocrine function. Therefore, the incidence of pancreatitis in such patients is considered to be low. However, tumor involvement to PD was not an indepen- 
- Table6 Univariate and multivariate analyses of risk factors for cholecystitis $(n=123)$.

\begin{tabular}{|c|c|c|c|c|c|c|c|}
\hline & & \multicolumn{3}{|l|}{ Univariate } & \multicolumn{3}{|c|}{ Multivariate } \\
\hline & & Odds ratio & $95 \% \mathrm{Cl}$ & $P$ value & Odds ratio & $95 \% \mathrm{Cl}$ & $P$ value \\
\hline Resectability status & BR & 1.21 & $0.30-4.82$ & 0.79 & & & \\
\hline Tumor involvement to OCD & Yes & 38.6 & $8.69-172$ & $<0.01$ & 38.6 & $8.69-172$ & $<0.01$ \\
\hline CBD angulation & $\leq 136$ degrees & 2.53 & $0.72-8.90$ & 0.15 & & & \\
\hline Gallbladder stone & Yes & 1.51 & $0.30-7.65$ & 0.62 & & & \\
\hline SEMS type & high AF & 1.03 & $0.21-5.12$ & 0.97 & & & \\
\hline SEMS length & $\leq 6 \mathrm{~cm}$ & 2.21 & $0.46-10.6$ & 0.32 & & & \\
\hline OCD occlusion by SEMS & Yes & 43900000 & $0-$ & 0.99 & & & \\
\hline
\end{tabular}

dent predictive factor in our study. We suppose that residual pancreas volume better correlates with exocrine function than tumor involvement to PD, resulting as a better predictive factor for pancreatitis. A large pancreatic volume calculated by volumetry was reported to be a risk factor for post-ERCP pancreatitis in the general population [32]. However, it is difficult and cumbersome to calculate the residual pancreas volume by volumetry in pancreatic cancer patients. Importantly, our study demonstrated that pancreatic volume index was an independent risk factor for pancreatitis.

On the other hand, cholecystitis developed in $9.8 \%$ of patients (12/123) after SEMS placement. Tumor involvement to OCD, SEMS of high AF, SEMS with short length, and gallbladder stones have been reported to be risk factors for cholecystitis after SEMS placement [29,33-35]. In our study, tumor involvement to OCD was the only independent risk factor, whereas SEMS of high AF or SEMS with short length were not. It has been speculated that compression at OCD by SEMS of high AF might cause tumor dislocation and deviation from the bile duct axis, resulting in impaired bile efflux and risk for cholecystitis [33]. However, we assume that angulation of CBD and anatomical variations of the cystic duct may also influence incidence of cholecystitis, hence affecting the results of our study. Unfortunately, CBD angulation was not a significant risk factor for cholecystitis in our study, possibly because the number of cholecystitis was relatively low to detect the difference.

As mentioned above, our study identified the following independent risk factors: (1) sharp CBD angulation for short duration of TRBO; (2) high pancreatic volume index and SEMS of high AF for pancreatitis; and (3) tumor involvement to OCD for cholecystitis. Therefore, it might be better to consider different stenting strategy for PC patients who have either of these risk factors. Because patients with BR PC sometimes fail to receive pancreatic resection when severe acute pancreatitis occurs, routine plastic stent exchange may be an option for high-risk patients with BR PC. On the other hand, endoscopic ultrasound-guided transmural SEMS placement such as choledochoduodenostomy might be an option for high-risk patients with UR PC. As for resectable PC, FCSEMS with low axial force would be the best choice for SEMS. However, as mentioned above, routine plastic stent exchange might also be an option for high risk patients.

Our study has several limitations. First, it was retrospective with a limited sample size. Second, we only evaluated stentrelated AEs after SEMS placement, which was usually performed in the second session. However, we suppose that this might also be a strong point because we could evaluate the direct impact of SEMS placement itself by excluding risk factors for post-ERCP pancreatitis, such as difficult cannulation. Furthermore, the incidence of stent-related severe pancreatitis was high in our study, probably because we included patients with BR PC who had a high pancreatic volume index in our analysis. Third, patients with R PC were not included in this study because we did not place a SEMS for those who were candidates for upfront surgery during the study period. Finally, we used the sum of length of the pancreatic parenchyma measured at three sections as a surrogate parameter for residual pancreas volume, which lacks accuracy compared to volumetry. Nonetheless, it is also technically difficult to accurately measure the remnant pancreas volume even by volumetry, because of distal pancreas atrophy and dilated PD. Furthermore, volumetry is very cumbersome and cannot be easily used in daily clinical practice. Therefore, a simple and easily calculated parameter is of critical importance. However, further studies are needed to validate the usefulness of pancreatic volume index.

\section{Conclusion}

In conclusion, we demonstrated that SEMS can be safely deployed even in patients with BR PC. Sharp CBD angulation and high pancreatic volume index were identified as novel risk factors for RBO and pancreatitis, respectively, after SEMS placement in patients with PC. Further studies with a larger sample size are warranted to validate our findings. 
Competing interests

Dr. Sasahira has received honoraria from Boston Scientific Japan and Cook Medical Japan. Dr. Sasaki has received honoraria from Boston Scientific Japan, Cook Medical Japan, and Century Medical Inc.

\section{References}

[1] Siegel RL, Miller KD, Jemal A. Cancer Statistics, 2017. CA Cancer J Clin 2017; 67: 7-30

[2] Lucas AL, Malvezzi M, Carioli G et al. Global Trends in pancreatic cancer mortality from 1980 through 2013 and predictions for 2017. Clin Gastroenterol Hepatol 2016; 14: 1452-1462.e1454

[3] Sasaki T, Kanata R, Yamada I et al. Improvement of treatment outcomes for metastatic pancreatic cancer: a real-world data analysis. In Vivo 2019; 33: 271-276

[4] Schnelldorfer T, Ware AL, Sarr MG et al. Long-term survival after pancreatoduodenectomy for pancreatic adenocarcinoma: is cure possible? Ann Surg 2008; 247: 456-462

[5] Cameron JL, He J. Two thousand consecutive pancreaticoduodenectomies. J Am Coll Surg 2015; 220: 530-536

[6] Versteijne E, Vogel JA, Besselink MG et al. Meta-analysis comparing upfront surgery with neoadjuvant treatment in patients with resectable or borderline resectable pancreatic cancer. Br J Surg 2018; 105 : 946-958

[7] Shubert CR, Bergquist JR, Groeschl RT et al. Overall survival is increased among stage III pancreatic adenocarcinoma patients receiving neoadjuvant chemotherapy compared to surgery first and adjuvant chemotherapy: An intention to treat analysis of the National Cancer Database. Surgery 2016; 160: 1080-1096

[8] Dhir M, Malhotra GK, Sohal DPS et al. Neoadjuvant treatment of pancreatic adenocarcinoma: a systematic review and meta-analysis of 5520 patients. World J Surg Oncol 2017; 15: 183

[9] Barenboim A, Lahat G, Geva R et al. Neoadjuvant FOLFIRINOX for locally advanced and borderline resectable pancreatic cancer: An intention to treat analysis. Eur J Surg Oncol 2018; 44: 1619-1623

[10] Ielpo B, Duran H, Diaz E et al. Preoperative treatment with gemcitabine plus nab-paclitaxel is a safe and effective chemotherapy for pancreatic adenocarcinoma. Eur ] Surg Oncol 2016; 42: 1394-1400

[11] Chawla A, Ferrone CR. Neoadjuvant therapy for resectable pancreatic cancer: an evolving paradigm shift. Frontiers Oncol 2019; 9: 1085

[12] Motoi F, Kosuge T, Ueno $\mathrm{H}$ et al. Randomized phase II/III trial of neoadjuvant chemotherapy with gemcitabine and S-1 versus upfront surgery for resectable pancreatic cancer (Prep-02/JSAP05). Jpn J Clin Oncol 2019; 49: 190-194

[13] Isayama H, Yasuda I, Ryozawa S et al. Results of a Japanese multicenter, randomized trial of endoscopic stenting for non-resectable pancreatic head cancer (JM-test): Covered Wallstent versus DoubleLayer stent. Dig Endosc 2011; 23: 310-315

[14] Almadi MA, Barkun A, Martel M. Plastic vs. self-expandable metal stents for palliation in malignant biliary obstruction: a series of metaanalyses. Am J Gastroenterol 2017; 112: 260-273

[15] Kubota K, Sato T, Watanabe $S$ et al. Covered self-expandable metal stent deployment promises safe neoadjuvant chemoradiation therapy in patients with borderline resectable pancreatic head cancer. Dig Endosc 2014; 26: 77-86

[16] Gardner TB, Spangler CC, Byanova KL et al. Cost-effectiveness and clinical efficacy of biliary stents in patients undergoing neoadjuvant therapy for pancreatic adenocarcinoma in a randomized controlled trial. Gastrointest Endosc 2016; 84: 460-466
[17] Siddiqui AA, Mehendiratta V, Loren D et al. Self-expanding metal stents (SEMS) for preoperative biliary decompression in patients with resectable and borderline-resectable pancreatic cancer: outcomes in 241 patients. Dig Dis Sci 2013; 58: 1744-1750

[18] Tsuboi T, Sasaki T, Serikawa M et al. Preoperative biliary drainage in cases of borderline resectable pancreatic cancer treated with neoadjuvant chemotherapy and surgery. Gastroenterol Res Pract 2016; 2016: 7968201

[19] Wasan SM, Ross WA, Staerkel GA et al. Use of expandable metallic biliary stents in resectable pancreatic cancer. Am J Gastroenterol 2005; 100: 2056-2061

[20] Tol JA, van Hooft JE, Timmer R et al. Metal or plastic stents for preoperative biliary drainage in resectable pancreatic cancer. Gut 2016; 65: 1981-1987

[21] Tempero MA, Malafa MP, Al-Hawary M et al. Pancreatic Adenocarcinoma, Version 2.2017, NCCN Clinical Practice Guidelines in Oncology. J Natl Compr Canc Netw 2017; 15: 1028-1061

[22] Kim KY, Han J, Kim HG et al. Late Complications and stone recurrence rates after bile duct stone removal by endoscopic sphincterotomy and large balloon dilation are similar to those after endoscopic sphincterotomy alone. Clin Endosc 2013; 46: 637-642

[23] Isayama H, Hamada T, Yasuda I et al. TOKYO criteria 2014 for transpapillary biliary stenting. Dig Endosc 2015; 27: 259-264

[24] Cotton PB, Eisen GM, Aabakken L et al. A lexicon for endoscopic adverse events: report of an ASGE workshop. Gastrointest Endosc 2010; 71: 446-454

[25] Kanda Y. Investigation of the freely available easy-to-use software 'EZR' for medical statistics. Bone Marrow Transplant 2013; 48: 452458

[26] Miura S, Kanno A, Masamune A et al. Risk factors for recurrent biliary obstruction following placement of self-expandable metallic stents in patients with malignant perihilar biliary stricture. Endoscopy 2016; 48: 536-545

[27] Keizman D, Shalom MI, Konikoff FM. An angulated common bile duct predisposes to recurrent symptomatic bile duct stones after endoscopic stone extraction. Surg Endosc 2006; 20: 1594-1599

[28] Yoo ES, Yoo BM, Kim JH et al. Evaluation of risk factors for recurrent primary common bile duct stone in patients with cholecystectomy. Scand J Gastroenterol 2018; 53: 466-470

[29] Shimizu S, Naitoh I, Nakazawa T et al. Predictive factors for pancreatitis and cholecystitis in endoscopic covered metal stenting for distal malignant biliary obstruction. J Gastroenterol Hepatol 2013; 28: 6872

[30] Kawakubo K, Isayama H, Nakai Y et al. Risk factors for pancreatitis following transpapillary self-expandable metal stent placement. Surg Endosc 2012; 26: 771-776

[31] Cote GA, Kumar N, Ansstas M et al. Risk of post-ERCP pancreatitis with placement of self-expandable metallic stents. Gastrointest Endosc 2010; 72: 748-754

[32] Maruyama H, Shiba M, Ishikawa-Kakiya Y et al. Positive correlation between pancreatic volume and post-endoscopic retrograde cholangiopancreatography pancreatitis. J Gastroenterol Hepatol 2019: doi:10.1111/jgh. 14878

[33] Nakai Y, Isayama H, Kawakubo K et al. Metallic stent with high axial force as a risk factor for cholecystitis in distal malignant biliary obstruction. J Gastroenterol Hepatol 2014; 29: 1557-1562

[34] Suk KT, Kim HS, Kim JW et al. Risk factors for cholecystitis after meta stent placement in malignant biliary obstruction. Gastrointest Endosc 2006; 64: 522-529

[35] Isayama H, Kawabe T, Nakai Y et al. Cholecystitis after metallic stent placement in patients with malignant distal biliary obstruction. Clin Gastroenterol Hepatol 2006; 4: 1148-1153 